\title{
Civilizaçâo, cultura e doença: revisitando Sigerist
}

SIGERIST, Henry E.

Civilization and Disease

2nd Ed. With a New Foreword by Elizabeth Fee

Ithaca, N.Y.: Cornell University Press, 2018, 255 p.

\section{| ${ }^{1}$ Everardo Duarte Nunes I}

1 Saúde Coletiva, Universidade Estadual de Campinas. Campinas-SP, Brasil (evernunes@uol.com.br). ORCID: 0000-0002-2285-7473

Recebido em: 22/11/2019

Aprovado em: 30/01/2020

Revisado em: 14/07/2020

DOI: http://dx.doi.org/10.1590/S0103-73312020300238

Books were treasured possessions and were treated like members of the family. Beeson (1997, p.97).

\begin{abstract}
A doença sempre teve lugar de relevo no curso da civilização, embora não haja dois fenômenos mais diferentes do que a doença - um processo material - e civilização - a criaçâo mais sublime da mente humana. A relação entre ambos, no entanto, é clara [...]. Como a doença existiu sempre, todas as instituições humanas lhe sentiram os efeitos e precisaram confrontá-la (SIGERIST, 2011, p. 1-2).
\end{abstract}

Esses são parágrafos escritos por Henry E. Sigerist (1891-1957) na Introdução do seu livro - "o clássico e frequentemente citado" (NORTON, 2019, p. 215) Civilization and Disease (SIGERIST, 1943) e reeditado em 2018 (SIGERIST, 2018). Essa reedição não altera a primeira, mas traz um elaborado prefácio bibliográfico escrito pela historiadora da ciência e da saúde pública Elizabeth Fee (1946-2018), profunda conhecedora da vida e obra de Sigerist, e que nos deixou recentemente (ORANSKY; MARCUS, 2018; LIMA; HOCHMAN, 2019). O prefácio não apenas informa sobre o autor, mas contextualiza suas ideias, produção histórica e atividades. Segundo (FEE, 2018, p. ix) “[o] livro fornece uma excelente introdução à 
obra de Sigerist”. Retomarei as esclarecedoras análises de Fee (1989, 1997, 2018), Fee e Brown (1997), Brown e Fee (1997) sobre essa obra, incluindo pesquisas recentes (ALMEIDA, 2016) que oferecem novas luzes sobre Sigerist e sua obra.

Em 1943, Sigerist agradece à Universidade de Cornell e à editora "pela permissão para transformar as seis conferências em livro de 12 capítulos". As Messenger Lectures foram pronunciadas na Universidade de Cornell, em Ítaca (estado de Nova York), durante o ano acadêmico de 1940 (28 outubro - 16 novembro). Essas conferências foram criadas, em 1924, pelo matemático Hiram J. Messenger (1855-1913) como "um fundo para fornecer um curso de palestras sobre a Evolução da Civilização com o objetivo especial de elevar o padrão moral de nossa vida política, comercial e social" (SIGERIST, 2011, p. xlviii). As conferências permanecem, até hoje, como importante atividade extracurricular, abrangendo as mais diversas áreas do conhecimento. Sigerist (1941, p. 397) relata que participar das Lectures "foi um tempo muito feliz", envolvido pela hospitalidade do corpo docente, administração e estudantes. Segundo Sigerist, a composição dos temas foi a seguinte:

1. Disease as a Factor in the Development of Civilization. 2. Disease, Social Life and Economics. 3. Disease, Religion and Philosophy. 4. Disease in Art and Literature. 5. Civilization as a Factor in the Genesis of Disease. 6. Civilization Fighting Disease.

Na década de 1940, Sigerist era um nome consagrado no campo da História da Medicina, das propostas para a reforma das políticas de saúde nos Estados Unidos (seguro-saúde obrigatório) e das reformulações no ensino médico. Sigerist chegou aos Estados Unidos em 1932. Nasceu na França, em 1891, filho de pais suíços, estudou filologia oriental (Zurique), línguas (Londres) e ao longo da sua vida dominou 14 idiomas; graduou-se em medicina (1917); praticou obstetrícia e estudou farmacologia experimental; participou do corpo médico do exército suíço durante a Primeira Guerra Mundial. Sempre evitou a especialização e encontrou na História da Medicina o campo para o qual dedicaria toda a sua vida: 1921-1924 - professorassistente de História da Medicina (Zurique); 1925-1932 - professor de História da Medicina e diretor do Instituto de História da Medicina da Universidade de Leipzig; 1932-1947 - professor de História da Medicina da Universidade Johns Hopkins. Em 1947 deixou Johns Hopkins e voltou para a cidade de Pura (Suíça), onde faleceu em 17 de março de 1957.

Editado em plena Segunda Guerra Mundial (1939-1945), o impacto do livro pode ser constatado quando a primeira edição de 1.500 exemplares se esgotou 
em seis meses; nos anos seguintes (1944 e 1945) foram impressas 3.000 cópias (MILLER, 1966, p. 25). Miller (1966) cita uma segunda edição americana, em 1962, da Universidade de Chicago (SIGERIST, 1962). Traduçôes foram feitas para espanhol (1946), alemão (1952), chinês (2009, 2016) e português (2011).

Outra fonte de informaçôes da primeira edição é constituída pelas inúmeras resenhas assinadas por médicos, historiadores, sociólogos, sanitaristas. Seelig (1944, p. 514) ressalta "o profundo interesse do autor nos problemas sociológicos da saúde”; Rosen (1944, p. 329) resume a proposta de Sigerist: “analisar os vários pontos pelos quais a civilização (ou cultura humana) e [como] a doença humana têm interagido e afetado mutuamente" e ressalta que Sigerist, com o livro, "traça um programa para a pesquisa" no campo histórico. Castiglioni (1944), por sua vez, destaca a erudição e conhecimento de Sigerist em bem documentada apresentação, inclusive pelas ilustrações. Para o sociólogo Queen (1944, p. 104), trata-se de "um interessante pequeno livro em estilo popular [escrito] por um homem com um título pouco comum (sic!) "professor de História da Medicina”. Para ele, há "muitas sugestôes", mas são de caráter introdutório e não sistematizado. Nessa linha de argumentação, o sociólogo Faris (1945) criticou, dizendo que falta unidade orgânica ao trabalho. Muitas dessas críticas, pouco lisonjeiras, parecem proceder de comentaristas que desconheciam a trajetória percorrida por Sigerist quando publicou o Civilization and Disease.

Sem dúvida, uma das questóes que envolve a melhor compreensão dessa obra situa-se no campo das tensôes entre as categorias civilizaçâo e cultura, especialmente trazidas pela tradição germânica. Geuss (1997, p. 153) aponta que "[e]m alemão, existem três palavras que são usadas no lugar de nossa "cultura": Kultur, Bildung e Geist". Apesar das "sombras", ou seja, serem termos com relaçóes semânticas muito próximas aos originais, "gradualmente se tornam cada vez mais nitidamente distintos do termo original, até que finalmente um par contrastante surja”.

No caso de Kultur, a sombra é Zivilisation. Kultur e Zivilisation começam a pouca distância um do outro e até têm uma gama de usos mais ou menos sobrepostos, mas, no início do século XX, os dois termos começaram a ser usados como membros de um par contrastante: o Zivilisation tem uma leve conotaçáo pejorativa e foi usada para se referir às armadilhas, artefatos e comodidades externas de uma sociedade industrialmente avançada e também aos hábitos e atitudes excessivamente formalistas e calculistas que se pensava serem característicos de tais sociedades. Kultur foi então usado para se referir a hábitos, atitudes e propriedades positivamente valorizados. (GEUSS, 1997, p. 154-155). 
Destaque-se, também, que foi durante o "período de Leipzig" (1925-1932) que Sigerist planejou as primeiras ideias sobre as relaçóes cultura e doença. Havia quatro departamentos no Instituto de História da Medicina e diferentes projetos: Medicina Geral - história do pensamento médico; Patologia - cultura e doença; Farmacologia - história de algumas drogas; e História Cultural - história das ideias, medicina medieval e barroca. No projeto Kultur und Krankheit, Sigerist (1928) enuncia as "afiliaçóes culturais" e "estilo" de certas doenças: a peste como uma epidemia das "grandes convulsôes sociais da Idade Média", a sífilis como típica da "atitude individualista da Renascença" (KASTNER, 1997, p. 49-50). Sigerist $(1928$, p. 6) inclui que "[o] complexo de sintomas da clorose parece estar ligado a um tipo definido de mulher jovem, uma vez que é mais claramente reconhecível aproximadamente no período Biedermeier". ${ }^{1}$

Temkin (1997, p. 126) comenta que, nessa fase, para Sigerist, as relaçóes artemedicina-arte eram orgânicas "expressing the same spirit", ou seja, que a história podia ser "bonita", "abordada com um olhar estético". Mas acrescenta:

Se, no fundo, Sigerist fosse romântico, ele poderia ter aderido a essa tese e tentado desenvolver suas possibilidades. Civilization and Disease reverte para o tema; mas este livro, publicado em 1943, é permeado por um espírito diferente. Ele mantém algumas das ideias antigas, mas também indica a crescente preocupação de Sigerist com interpretaçóes sociais, econômicas e políticas. A mudança de uma orientação mais idealista para uma materialista na história da medicina foi paralela ao crescente interesse de Sigerist pela sociologia médica [...]. (TEMKIN, 1997, p. 126 - grifos nossos).

De outro lado, Fee (1989, p. 132 - grifos nossos) acrescenta: “[o] primeiro esforço de Sigerist para vincular a doença à civilização foi, portanto, abstrato, simbólico $e$ idealista; gradualmente, seria suplantado por uma concepção mais materialista da causa da doença". Em outra passagem, Fee e Brown (1997, p. 185-186 - grifos nossos) comentam que "[Sigerist] lutou para romper uma nova historiografia consistente com sua visáo social e político social" e que isso demorou por longos períodos. Citam que em Civilization and Disease, "ele começou com dois novos capítulos sobre as determinaçôes materiais e econômicas da doença e depois recaiu em nove capítulos sobre fatores culturais [...].

Em seu comentário mais recente, Fee (2018, p. x) aponta que "ao enfatizar sobre as conexóes entre filosofia e doença, literatura e doença, e as artes e doença, Sigerist demonstrou seu próprio e amplo interesse e conhecimento da cultura de muitas épocas". Norton (2019, p. 215) ressalta que no capítulo "Disease and law", ele escreve 
"um esclarecedor ensaio sobre o dilema da doença mental e do crime que poderia ter sido escrito ontem". Considero que a reedição do livro e seus 12 capítulos constitui uma rara oportunidade de sua releitura e o alerta em sua apresentação ao público marca a seriedade desta edição, ao considerar que "[a]pesar dos consideráveis avanços na medicina e na historiografia", o livro "continua sendo um trabalho de referência na história da medicina [...]” (GOOGLE BOOKS, 2019).

Questão importante ao se reanalisar essa obra é que as concepçóes culturais e a visão ampliada do pensamento de Sigerist sobre a doença foram retomadas e revisitadas no momento em que arquivos pessoais e de trabalho, incluindo os cursos ministrados por Canguilhem (1904-1995), preservados no Centre d'Archives em Philosophie, Histoire et Édition des Sciences (CAPHÉS - CNRS/ENS) foram abertos (embora não possam ser publicados). Em um detalhado trabalho de pesquisa aos documentos inéditos, que resultou em seu doutoramento, Almeida (2016) analisa os trabalhos de Canguilhem numa perspectiva histórica e epistemológica, trazendo à tona suas relações com a obra de Sigerist.

Desde a publicação do seu doutorado [medicina], em 1943, Canguilhem referese de forma elogiosa a um livro anterior de Sigerist considerando que Einführung in die Medizin (SIGERIST, 1931), citado em sua tradução francesa (SIGERIST, 1932), "uma explanação sumária e magistral de toda essa evolução das ideias médicas" (ALMEIDA, 2016, p. 73).

Sem dúvida, a importância atribuída por Canguilhem está expressa ao afirmar: "A medicina", disse Sigerist, "é uma das ciências mais estreitamente ligada ao conjunto da cultura, toda transformação nas concepções médicas sendo condicionadas por transformaçóes nas ideias de uma época”. A teoria que acabamos de expor ao mesmo tempo médica, científica e filosófica, comprova perfeitamente essa proposição [extraída do livro Introduction à la Médecine]. Parece-nos que ela satisfaz simultaneamente a diversas exigências e postulados intelectuais do momento histórico da cultura no qual ela foi formulada" (ALMEIDA, 2016, p. 79). Além dessas, há outras citaçôes do livro de Sigerist (CANGUILHEM, 1978, p. 22, 77, 90, 144, 165, 168).

Interessante incluir neste momento a polêmica que foi criada pelo historiador Ernest Wickersheimer (1880-1965) sobre a originalidade da relação cultura e doença em Sigerist, que teria sido precedida pela de Émile Littré (1801-1881 relatada por Almeida (2016, p. 66-71), do qual são tomados alguns pontos. O texto de Wickersheimer é de 1929 e relata que, segundo Sigerist, “[...] a doença é largamente 
influenciada pelas condiçôes gerais da existência. Ideia muito justa, embora não muito nova”. E prossegue, "[a] originalidade no estabelecimento das relaçôes entre 'a patologia de uma época' e 'o gênero de vida que então levavam as diversas classes da sociedade”, pertence a Émile Littré, desde seus estudos sobre epidemias de 1836. Atribui a Sigerist apenas um "curioso" esforço de "perseguir a ideia de Littré até as suas últimas consequências", a saber, "uma sincronia necessária entre os fatos da história das doenças e os fatos da história geral".

Segundo Almeida (2016, p. 66), "[a] sugestão de continuidade entre as ideias de Sigerist e as de Littré parecia plausível no momento em que Wickersheimer escrevia”. No entanto:

Em 1930, ano seguinte à publicação do artigo de Wickersheimer, o Instituto de História da Medicina da Universidade de Leipzig, do qual Sigerist era o diretor, adquiriu através de leiláo um manuscrito de Littré sobre Charles Daremberg. O manuscrito, datado de fevereiro de 1862, foi publicado no Sudhoffs Archiv für Geschichte der Medizin com uma breve apresentação de Sigerist [...] "A moderna história da medicina teve seu ponto de partida na França. Littré e Daremberg são seus porta-vozes”.

Como escreve Almeida (2016, p. 67-68):

Sigerist acreditava que o manuscrito de Littré era uma espécie de carta de recomendação para a primeira cadeira de história da medicina na França, criada em 1870, antes mesmo da criação da primeira cadeira de história geral das ciências. [...] Wickersheimer não compreendeu que "Kultur und Krankheit" era um sinal do afastamento de Sigerist da sombra paterna de Karl Sudhoff, a quem também pagava tributos pela sua abordagem filológica da história da medicina, e, ao mesmo tempo, um sinal da aproximaçáo das ideias de Oswald Spengler e sua morfologia cultural.

Todas as aproximaçóes feitas nesta resenha tiveram o objetivo de analisar uma obra carregada de significaçôes e controvérsias, mas como escreveu o próprio autor, foi a oportunidade de "selecionar um tópico para o meu curso no qual trabalhei por muitos anos, a saber, Civilization and Disease" (SIGERIST, 1941, p. 397).

Esta edição, em seu conteúdo central, apresenta nos três capítulos iniciais aspectos das transformaçóes civilizatórias na gênese das doenças influenciadas por três dimensões: a nutrição, o vestuário e a habitação; configura em seguida, a relação doença e economia mediada pelo trabalho, riscos industriais e de forma pioneira enuncia um tema que se tornaria frequente na atualidade "a determinação econômica e a distribuição social da enfermidade" e encerra com "as consequências econômicas da doença” e, no terceiro capítulo, trata da doença e a vida social. Neste 
capítulo, trata especialmente da história da atitude da sociedade diante do homem doente, do leproso, do sifilítico, doente mental. Os capítulos seguintes, muitas vezes considerados como tratando de aspectos culturais relacionados à doença, abordam as relações com a lei, história, religião, filosofia, ciência, literatura, arte e música. O capítulo final denominado "Civilization against disease", Sigerist (2018, p. 230) toma como orientação que a "[a] história da medicina reflete a história da civilização" e que a medicina não é somente um ofício, mas "parte do saber geral de uma época", "reflete uma visão de mundo". Um breve epílogo encerra o livro, escrito quando "a civilização parece estar em ruínas" (Segunda Guerra Mundial), mas Sigerist mostra-se otimista quanto ao "futuro da humanidade" - cooperante, democrática, científica, preservadora dos direitos e deveres iguais para todos de fato.

Algumas observaçóes devem ser ressaltadas: cada capítulo pode ser lido separadamente; os três primeiros abordam aspectos estruturais da sociedade e os demais sobre os saberes que as culturas constroem sobre a doença. Resultam de um acúmulo de pesquisas realizadas e que ainda prosseguiram até a década de 1950 quando Sigerist (1951) publicou o primeiro volume da sua projetada obra sobre a história da medicina em oito volumes, sendo que o segundo somente foi publicado após seu falecimento (SIGERIST, 1961).

Acentue-se que as aproximaçôes se situaram dentro da época em que a obra foi produzida centrada na análise das concepçôes de civilização e cultura. Não se trata de, neste momento, reaproximar a discussão a partir dos novos enfoques, mas observar que esse tema continua desafiando os estudiosos. Rojeck (2006) refaz brevemente o caminho histórico-conceitual do termo ao tratar do lazer. Recorda que, no discurso cotidiano, frequentemente, os termos são apresentados como intercambiáveis, mas para ele:

Ambos os termos significam continuidades distintas nos padrôes coletivos de comportamento. Continuidades são entendidas como influências facilitadoras e restritivas sobre o comportamento individual. Cultura refere-se a continuidades localizadas relacionadas "a princípios e práticas costumeiros e profundamente enraizados de inclusão e exclusão" Em contraste, Civilização é construída de materiais culturais e transculturais que permite níveis de governo, cultura e modos de vida que são avaliados racionalmente como "mais altos" ou "superiores". Como a civilização é constituida de recursos culturais há alguma confusão sobre onde a civilização começa e a cultura termina. (grifos nossos).

Civilization and Disease exemplifica bem essa questão. ${ }^{2}$ 


\section{Referências}

ALMEIDA, T. S. Georges Canguilhem: combates pela história das ciências. 2016, 220 p. Tese (Doutorado em História Social) São Paulo) - Faculdade de Filosofia, Letras e Ciências Humanas, Universidade de São Paulo, São Paulo, 2016.

BEESON, N. S. My Father, H.E.S.: A Photo Essay. In FEE, E.; BROWN, T.M. (Ed.). Making Medical History: The Life and Times of Henry E. Sigerist. Baltimore: The Johns Hopkins University Press, 1997. p. 93-117.

BROWN, T. M. FEE, E. "Anything bur Amabilis": Henry Sigerist"s Impact on the History of Medicine in America. I. In: FEE, E., BROWN, T.M. (Ed.). Making Medical History: The Life and Times of Henry E. Sigerist. Baltimore: The Johns Hopkins University Press, 1997. p. 333-370.

CANGUILHEM, G. O Normal e o Patológico. Rio de Janeiro: Forense Universitária, 1978. 270 p. CASTGliOnI, A. Civilization and Disease by Henry E. Sigerist Review. The American Historical Review, v. 49, n. 4, p. 689-690, 1944.

FARIS, R. E. L. Civilization and Disease by Henry E. Sigerist Review. American Journal of Sociology, v. 50, n, 3, p. 237-237, 1944.

FEE, E. Foreword, The life and work of Henry E. Sigerist. In: SIGERIST, H. E. Civilization and Disease. Ithaca, New York: Cornell University Press, 2018. p. ix-xii.

. Henry E. Sigerist: From the Social Production of Disease to Medical Management and Scientific Socialism. The Milbank Quarterly, v. 67, suppl. 1989, p. 127-150.

. The pleasures and perils of prophetic advocacy: Henry E. Sigerist and the politics of medical reform. In: FEE, E., BROWN, T. M., Making Medical History: The Life and Times of Henry E. Sigerist. Baltimore: Johns Hopkins University Press, 1997. p. 197-228.

FEE, E.; BROWN, T. M. Intellectual legacy and political quest: the shaping of a historical ambition”. In: FEE, E.; BROWN, T. M. (Eds.). Making Medical History: The Life and Times of Henry E. Sigerist. Baltimore: Johns Hopkins University Press, 1997. p. 179-193.

FIGLIO, K. Chlorosis and Chronic Disease in Nineteenth-Century Britain: The Social Constitution of Somatic Illness in a Capitalist Society. Social History, v. 3, n. 2, p. 167-197, 1978.

GOOGLE BOOKS. Civilization and Disease. Disponível em: https://books.google.com.br/ books/about/Civilization_and_Disease.html?id=ihdiDwAAOBAJ\&redir_esc=y. Acesso em: 21 nov. 2019.

GUESS, R. Kultur, Bildung, Geist History and Theory, v. 35, n. 2, p. 151-164, 1996.

KÄSTNER, I. The Leipzig Period, 1925-1932. In: FEE, E.; BROWN, T. M. (Eds.). Making Medical History: The Life and Times of Henry E. Sigerist. Baltimore: Johns Hopkins University Press, 1997. p. 42-80. 
LIMA, N. T.; HOCHMAN, G. Impact of Elizabeth Fee's Ideas and Scholarship for Brazil and the Global South. American Journal of Public Health , v. 109, n. 6, p. 872-873, 2019.

MILLER, G. A bibliography of the writings of Henry E. Sigerist. Montreal (Quebec): McGill University Press; 1966. 112 p.

NORTON, M. J. Book Review - Sigerist, Henry E. Civilization and Disease. Journal of the Medical Library Association. v. 107, n. 1, p. 115, 2019.

ORANSKY, I.; MARCUS, A. Elizabeth Fee. Lancet, v. 392, n. 10160, p. 2164, 2018.

QUEEN, A. S. Civilization and Disease by Henry E. Sigerist Review. American Sociological Review, v. 10, n. 1, p. 104-104, 1945.

ROJEK, C. Leisure, Culture and Civilization. In: ROJEK C.; SHAW, S. M.; VEAL, A. J. (Eds). A Handbook of Leisure Studies. London: Palgrave Macmillan, 2006. P. 25-40.

ROSEN, G. Civilization and Disease by Henry E. Sigerist Bulletin of the History of Medicine. v. 16, n. 3, p. 328-329, 1944.

SEELIG, M. G. Civilization and Disease by Henry E. Sigerist Review Science v. 99, n. 2582, p. 514-515, 1944.

SIGERIST, H. E. A History of Medicine. V. 1: Primitive and Archaic Medicine. New York: Oxford University Press, 1951. 564 p.

. Civilização e doença. São Paulo: Hucitec, Sobravime: Campinas, SP: SindMed, 2011. 346p.

. Civilization and Disease. (With a New Foreword by Elizabeth Fee). Ithaca, New York: Cornell University Press, 2018, 300 p.

. Civilization and Disease. 2. ed. Phoenix Science Series 511. Chicago: University of Chicago Press, 1962, 255.

. Civilization and Disease. Ithaca, New York: Cornell University Press, 1943.

. Einführung in die Medizin. Georg Thieme: Leipzig, 1931.

_. Introduction à la médecine. Tradução de Maurice Tenin. Paris: Payot, 1932.

. Kultur und Krankheit. Kiklos, v. 1, p. 147156, 1928.

_. The Johns Hopkins Institute of the History of Medicine during the Academic Year 1940-1941. Bulletin of the History of Medicine, v. 10, n. 2, 1941, p. 364-416, 1941.

TEMKIN, O. Henry E. Sigerist and aspects of medical historiography. In: FEE, E.; BROWN, T. M. (Eds.). Making Medical History: The Life and Times of Henry E. Sigerist. Baltimore: Johns Hopkins University Press, 1997. p. 121-135. 


\section{Notas}

${ }^{1}$ Figlio (1978, p. 175) comenta que "Sigerist nos direciona não apenas para o período entre 1820 e 1850, mas também para uma característica da sociedade alemã. Biedermeier era um termo satírico usado para representar uma classe e mentalidade doméstica de mente estreita, autossatisfeita, conservadora e cumpridora da lei. Talvez "pequeno-burguês" seja um termo adequado - um grupo à margem da classe média cuja própria marginalidade gerou uma imitação exagerada de comportamento "respeitável".

${ }^{2}$ Agradeço ao Conselho Nacional de Desenvolvimento Científico e Tecnológico (CNPq), pela Bolsa de Produtividade IA - processo 303983/2014-0. 